\title{
The Protective Effect of Carnitine in Human Diphtheric Myocarditis
}

\author{
ANTÔNIO CARLOS MARQUES FIGUEIREDO RAMOS, PAULO ROBERTO P. ELIAS, \\ LOUIS BARRUCAND, AND JOSÉ ANANIAS FIGUEIRA DA SILVA

\begin{abstract}
Serviço de Cardiologia do Instituto de Puericultura e Pediatria Martagão Gesteira [A.C.M.R.], Departamento de Bioquimica Médica, Instituto de Ciências Biomédicas [P.R.P.E.], Departamento de Patologia, Faculdade de Medicina [L.B.], and Serviço de Cardiologia, Hospital Universitário [J.A.F.d.S.], Centro de Ciências da Saude, Universidade Federal do Rio de Janeiro, 21941, Cidade Universitária, Ilha do Fundâo, Rio de Janeiro, Brasil
\end{abstract}

\section{Summary}

Carnitine, an important cofactor in the transport of fatty acids to the interior of cell mitochondria, is depleted in myocardial tissue of guinea pigs submitted to diphtheric toxin administration. Mortality rates were reduced in these animals by supplying exogenous amounts of carnitine. The accumulation of fatty acids in the cytoplasm of human heart cells reported in cases of diphtheria suggests that carnitine might possibly be depleted in human myocardium as well.

For the purpose of studying the effect of carnitine administration, 132 diphtheric patients were randomly divided into two groups, one of them (carnitine-treated group, $n=73$ ) receiving DL-carnitine, $100 \mathrm{mg} / \mathrm{kg} /$ day during 4 days after admission, in addition to routine treatment, which was prescribed for this and the control group $(n=59)$. The presence of myocardial damage was evaluated by clinical, electrocardiographic, radiological, and enzymatic criteria. Carnitine administration resulted in decreased incidence of heart failure $(P=0.0475)$, of pacemaker implants $(P=0.0256)$, and of lethality indexes due to myocarditis $(P=$ 0.013 ). We suggest that carnitine can play an important role in the treatment of diphtheric patients.

\section{Abbreviation}

CK-MB, creatine kinase MB isozyme

Diphtheria is an acute infectious disease which remains an important public health problem in many countries. Its etiologic agent is Corynebacterium diphtheriae, described first by Klebs in 1883 (11). The virulence of $C$. diphtheriae is directly related to its capacity to synthesize and excrete an exotoxin, responsible for the majority of clinical manifestations of the disease. The control of diphtheria in underdeveloped countries has been difficult, not only because of low primary immunization levels but also due to high virulence and relatively low pathogenicity of the bacteria. As a result, asymptomatic carriers as well as patients with subclinical infections are numerous (1). The diphtheria toxin can act on a culture of cells by inhibiting protein synthesis (10). This is accomplished by catalyzing the coupling of NAD to the cell elongation factor 2 (EF2), which is responsible for the incorporation of amino acids to peptides through soluble

Received December 30, 1983.

Correspondence may be addressed to Dr. Antônio Carlos M. F. Ramos, Serviço de Cardiologia, Instituto de Puericultura e Pediatria Martagão Gesteira, Universidade Federal do Rio de Janeiro, Cidade Universitária, Ilha do Fundão 21910, Rio de Janeiro, Brasil.

This work was supported by Conselho Nacional de Desenvolvimento Cientifico,
tRNA. The catalyst of this reaction is the fragment $A$ of the toxin molecule: $\mathrm{NAD}^{+}+\mathrm{EF} 2 \rightleftharpoons \mathrm{ADP}$-ribosyl-EF2 + nicotinamide $+\mathrm{H}^{+}$

According to Pappenheimer (16), blocking of the protein synthesis by fragment $A$ could lead to serious disturbances in cellular metabolism and consequently to its structure. It is conceivable that the maintenance of protein synthesis is a sine qua non condition to produce the necessary carriers for the transport of carnitine across the cardiac cell external membrane, as suggested by Bohmer and Molstad (3). Carnitine ( $\beta$-hydroxy- $\gamma-N$ trimethylammonium butyrate) is an indispensable cofactor for the transport of fatty acids to the interior of mitochondria, where they are oxidized to obtain ATP. As fatty acids are important fuels to the heart due to higher yield of ATP per molecule of oxidized fatty acid, carnitine is regularly accumulated in the cytoplasm of the cardiac cell so that relatively lower amounts of carnitine are found in circulating blood (17). The dependence of $60-70 \%$ of oxidative metabolism in the burning of fatty acids (15) makes imperative the entrance and accumulation of carnitine within the cardiac cell. A possible reduction in the number of carriers as an effect of interference in protein synthesis caused by the diphtheric toxin could lead to an impairment in carnitine transport and thus to a loss of carnitine molecules readily utilizable in the oxidative metabolism. Indeed, carnitine depletion from myocardium is a documented characteristic of diphtheria (19). The same goes to the expected accumulation of fatty acids in the cytoplasm of the heart cell of guinea pigs (7) and of human beings (5). Challoner et al. (6) attempted to counterbalance this depletion of carnitine by the administration of exogenous amounts of the substance to guinea pigs. The treated animals showed a reduction in death by heart involvement. These experiments also showed that carnitine administration after 4 days of treatment was ineffective, indicating no apparent advantage in prolonging it. By increasing the concentration of L-carnitine in the cell culture, Bohmer and Molstad showed that there was a concomitant increase of carnitine uptake by more than $50 \%$.

All the above described results give enough evidence that the administration of carnitine could in some way replenish the cardiac cell loss caused by the $C$. diphtheriae toxin. Therefore, carnitine treatment was tried by us with the hope that a larger number of myocardial cells would become viable and, consequently, there would be a reduction of clinical signs and a decrease in lethality coefficients related to myocarditis.

Carnitine has been used successfully in patients with systemic deficiency of this metabolite in many instances $(8,18)$, showing good oral absorption and absence of toxicological effects. DLCarnitine given to our patients has been also used therapeutically as a component of orexigenic medicines although there is no support for conclusive results of its efficiency in this respect. 


\section{MATERIALS AND METHODS}

All patients were prospectively observed from their admission to Hospital Estadual São Sebastião (a state hospital exclusively treating communicable diseases in the metropolitan area of Rio de Janeiro). During 1 year, 147 diphtheric patients were admitted and included in this study. Patients who died before $48 \mathrm{~h}$ of hospitalization $(n=15)$ were excluded from comparative analysis since in almost all cases it was impossible to submit them to the entire routine for diagnosis of myocarditis (Fig. 1). The remaining 132 patients were randomly distributed into two groups: the carnitine-treated group $(n=73)$ which was given a syrup of $10 \%$ DL-carnitine supplied in the chloride salt form by SapchimFournier-Cimag, along with the hospital's routine treatment for diphtheria. The total carnitine dose administered per day was $100 \mathrm{mg} / \mathrm{kg}$ of body weight, given in two portions during 4 days of treatment after admission. The control group $(n=59)$ consisted of patients receiving only routine hospital therapy: antidiphtheric serum in a single endovenous dose $(40,000$ to 80,000 units), penicillin (procaine + aqueous) in 400,000 units twice a day during 10 days (or erythromycin in those cases of hypersensibility to penicillin) and general support measures. For cardiac failure, the first choice was furosemide $(1-2 \mathrm{mg} / \mathrm{kg} /$ day $)$; digitalis (digoxin) was restricted to those patients when diuretic administration was useless or to those cases with early severe heart failure. Temporary cardiac pacemakers were implanted in those cases with severe advanced conduction disorders, according to recent experiments (13). Clinical characteristics of both groups at hospital admission are displayed in Table 1.

Once bacteriological diagnosis for diphtheria was confirmed, the presence, intensity, and evolution of myocarditis (based on repeated clinical, electrocardiographic, and radiological examinations) were evaluated in all patients. In this respect, it is worthwhile to mention that the levels of creatine kinase $\mathrm{MB}$ isoenzyme (EC 2.7.3.2) were also determined in at least two samples of blood per patient as another mean of evaluating heart injury. The determinations of CK-MB, which were based on the immunological inhibition of the M-type subunit of CK (20), were monitored continuously in a Cary model $118-\mathrm{C}$ recording spectrophotometer with the cell turret maintained at the temperature of $25^{\circ} \mathrm{C}$ by means of a Forma Scientific circulating water bath. Although reference values for this method range from 0 10 units/liter of blood, we obtained our own reference values from eight normal patients of the same age, submitted to statis- tical analysis, showing a maximal value of $11.26 \mathrm{U} /$ liter. Reagents for CK-MB assays were supplied by Merck in kit form (No. 15808). Muscular dystrophy of any kind was not present in the cases evaluated by $\mathrm{CK}-\mathrm{MB}$, thus increasing heart specificity in elevated levels.

Statistics consisted of a test involving difference of proportions for single samples (2), to test the hypothesis $H_{0}: p_{1}=p_{2}$. A Burroughs model 6700 computer was used to perform all calculations, according to the formula: $z=\left(\rho_{1}-\rho_{2}\right) / \sigma_{\rho_{1}-\rho_{2}}$, in which $\sigma_{\rho_{1}-\rho_{2}}=\sqrt{ } \rho(1-\rho)\left(1 / N_{1}+1 / N_{2}\right)$. Statistical significance was reached when $P<0.05$. Informed consent was obtained from patients' parents at admission.

\section{RESULTS}

Extensive myocardial damage is frequently evidenced by alterations in the physical examination of the cardiovascular system, as is the case of signs of heart failure, low output syndromes, muffled heart sounds, or regurgitant systolic apical murmurs. We observed a significant reduction $(P=0.0052)$ in the carnitinetreated group in comparison to the control one of the incidence of such alterations (Table 2).

The increase in cardiothoracic index by radiological examination was also significantly lower $(P=0.0418)$ in the carnitinetreated group, compared to control (Table 2).

Serial electrocardiograms (Table 2) showed no significant differences in the two groups in respect to the various electrocardiographic changes, although the difference in conduction disturbance incidence of any degree between the two groups was near the level of statistical significance $(P=0.0655)$.

CK-MB activities showed no statistical differences among all patients (Table 2), suggesting that carnitine administration has no influence on the early pathogenic process of diphtheric myocarditis itself, when a cellular lesion is associated with permeability alterations of the cytoplasmic membrane, leading to a release of the enzyme. The incidence of cases in which CK-MB levels were the sole sign of myocardial damage was not higher in the carnitine-treated group $(P=0.0749)$. Table 3 shows the correlation between the various ranges of CK-MB activities and the clinical evolution of the patients, irrespective of each group. It is noteworthy that $\mathrm{CK}-\mathrm{MB}$ ranges showed a prognostic value: in those cases within normal (reference) ranges of CK-MB activities, only one patient died due to myocarditis. In this latter case,

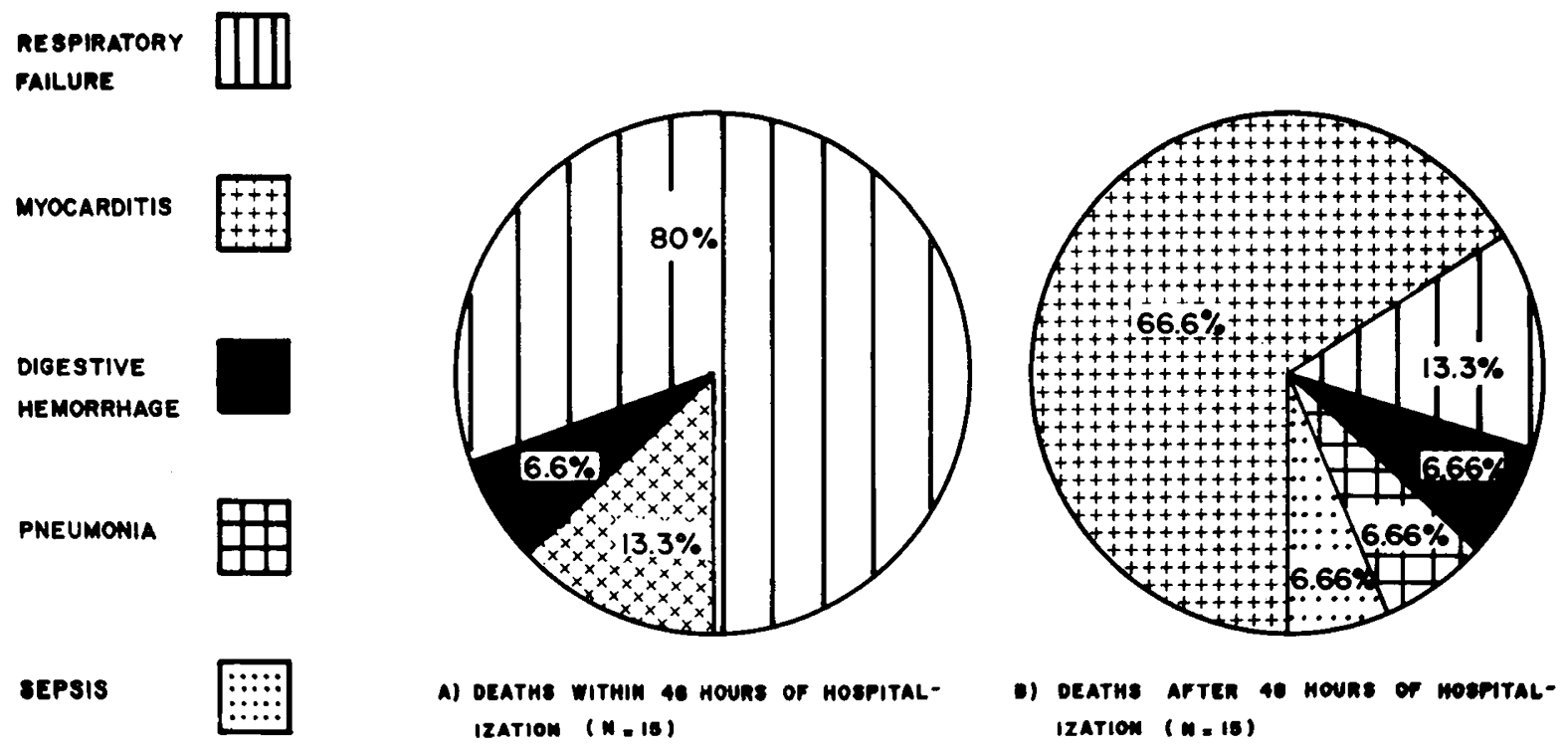

Fig. 1. Percentage of lethal causes in 147 patients studied. Note the high incidence of deaths by respiratory failure $(A)$ in contrast with higher incidence of deaths by myocarditis which occurred after $48 \mathrm{~h}$ of hospitalization $(B)$. 
Table 1. Clinical characteristics of control and carnitine-treated groups at admission

\begin{tabular}{|c|c|c|}
\hline \multirow{2}{*}{$\begin{array}{c}\text { Clinical } \\
\text { characteristics* }\end{array}$} & \multicolumn{2}{|c|}{ Number of cases (\%) } \\
\hline & Control & Carnitine-treated \\
\hline \multicolumn{3}{|l|}{ Age (years) } \\
\hline$<1$ & $5(8.5)$ & $11(15.1)$ \\
\hline $1-4$ & $32(54.2)$ & $37(50.7)$ \\
\hline $5-9$ & $17(28.8)$ & $23(31.5)$ \\
\hline $10-14$ & $4(6.8)$ & $1(1.4)$ \\
\hline$>14$ & $1(1.7)$ & $1(1.4)$ \\
\hline \multicolumn{3}{|l|}{ Sex } \\
\hline Male & $31(52.5)$ & $38(52.1)$ \\
\hline Female & $28(47.4)$ & $35(47.9)$ \\
\hline \multicolumn{3}{|l|}{ Color } \\
\hline White & $29(49.2)$ & $39(53.4)$ \\
\hline Mulatto & $26(44.1)$ & $26(53.6)$ \\
\hline Negro & $4(6.8)$ & $8(11)$ \\
\hline \multicolumn{3}{|l|}{ Immunization status $\dagger$} \\
\hline Nonvaccinated & $47(79.6)$ & $52(71.2)$ \\
\hline Incompleted vaccination & $4(6.8)$ & $12(16.5)$ \\
\hline Vaccinated & $8(13.6)$ & $9(12.3)$ \\
\hline \multicolumn{3}{|l|}{$\begin{array}{l}\text { Onset of symptoms prior to } \\
\text { admission (days) }\end{array}$} \\
\hline$\leqslant 3$ & $28(47.4)$ & $37(50.7)$ \\
\hline $4-6$ & $25(42.1)$ & $24(32.8)$ \\
\hline$\geqslant 7$ & $6(10.5)$ & $12(16.4)$ \\
\hline Fever & $53(89.8)$ & $66(91.4)$ \\
\hline Severe toxemia & $12(20.6)$ & $19(26)$ \\
\hline Severe respiratory failure & $15(25.4)$ & $14(19.2)$ \\
\hline Cervical edema ("bull neck”) & $21(35.6)$ & $24(32.9)$ \\
\hline
\end{tabular}

* Statistical difference of proportions are not significant for all parameters.

† Complete immunization schedule consists of three doses plus two booster doses (according to Ministério da Saúde, Brasil).

Table 2. Myocarditis incidence by several criteria in diphtheric patients

\begin{tabular}{lrcc}
\hline & \multicolumn{2}{c}{ Number of cases (\%) } & \\
\cline { 2 - 3 } & Control & Carnitine-treated & $P$ \\
\hline $\begin{array}{l}\text { Alterations in physical exami- } \\
\quad \text { nation of cardiovascular }\end{array}$ & $28(47.5)$ & $19(26)$ & $<0.05$ \\
$\quad$ system & & & \\
$\begin{array}{l}\text { Cardiac enlargement at radio- } \\
\quad \text { logical examination }\end{array}$ & $14(24.1)$ & $9(12.5)$ & $<0.05$ \\
Electrocardiographic changes & & & \\
$\quad$ Arrythmias & $9(15.3)$ & $8(10.9)$ & NS* \\
Conduction disturbances & $11(18.6)$ & $7(9.5)$ & NS \\
QRS changes & $9(15.3)$ & $6(8.2)$ & NS \\
S-T segment alterations & $10(16.9)$ & $10(13.7)$ & NS \\
$\quad$ T wave alterations & $19(32.2)$ & $20(27.4)$ & NS \\
Increased CK-MB levels & $18(30.5)$ & $21(28.8)$ & NS \\
\hline
\end{tabular}

*NS, nonsignificant.

this result was inconclusive as only a single measurement was obtained 5 days prior to death. Conversely, when CK-MB activities were greater than $20 \mathrm{U} /$ liter, seven patients died because of myocarditis and six had cardiac abnormalities after hospital discharge.

Figure 2 shows the overall incidence of myocarditis, which is similar in both groups.

The need for diuretics and/or digitalis in clinical sets of cardiac failure was significantly reduced $(P=0.0475)$ in the carnitine-
Table 3. Relation of $C K-M B$ levels to myocarditis evolution

\begin{tabular}{lccc}
\hline & $\begin{array}{c}\text { Deaths } \\
\text { due to } \\
\text { myocarditis }\end{array}$ & $\begin{array}{c}\text { Cardiac } \\
\text { abnormalities } \\
\text { at discharge }\end{array}$ & $\begin{array}{c}\text { Discharge } \\
\text { without } \\
\text { cardiac } \\
\text { abnormalities }\end{array}$ \\
\hline $\begin{array}{c}\text { CK-MB activities within } \\
\text { normal range }\end{array}$ & 1 & 2 & 37 \\
$\begin{array}{c}\text { CK-MB activities within } \\
\text { range 11.26-20 U/liter }\end{array}$ & 0 & 10 & 44 \\
$\begin{array}{c}\text { CK-MB activities higher } \\
\text { than 20 U/liter }\end{array}$ & 7 & 6 & 17 \\
\hline
\end{tabular}

treated group ( $n=11.9 \%$ ) when compared to control $(4.1 \%)$. Similarly, the indication to implant temporary cardiac pacemakers for the control of severe conduction disorders was significantly lower $(P=0.0256)$ in the carnitine-treated patients $(4.1 \%)$ in comparison to control $(13.8 \%)$.

Cardiac abnormalities persisted in eight patients of the control group and in 12 patients of the carnitine-treated group. The most frequent abnormalities observed at hospital discharge were electrocardiographic (conduction disturbances such as left anterior hemiblock, necrosis patterns, low QRS complex amplitudes, and repolarization changes), radiological (increased cardiac size), and clinical (systolic apical murmurs and pathological third heart sound).

Although not statistically significant $(P=0.102)$, overall lethality indexes were reduced in the carnitine-treated group $(8.2 \%)$ in comparison with the control group (15.3\%), but a significant reduction $(P=0.013)$ in lethality could be observed when myocarditis was considered as causa mortis (Table 4).

\section{DISCUSSION}

The increase in CK-MB activities showed greater accuracy in the determination of myocardial involvement. Interestingly, $\mathrm{CK}$ MB levels were relatively constant in most of the two samples collected in each patient: one in the first days after hospitalization and the other approximately 15 days after diphtheria symptoms appeared. This contrasts sharply with $\mathrm{CK}-\mathrm{MB}$ activity measured in uncomplicated infarction, which decreases in the blood after $12 \mathrm{~h}$ due to its rapid clearance in plasma. It is possible then to assume that leakage of CK-MB, which is "constant" in diphtheric myocarditis, is due to a diffused inflammatory process rather than a focal one, not necessarily related to ischemia. It is relevant to note that in 20 cases (six in control and 14 in the carnitinetreated group) CK-MB activity was the sole manifestation of myocardial damage. We could consider such cases as subclinical forms of myocarditis if CK-MB activities alone actually reflect subclinical myocardial damage. Although the difference in the incidence of such subclinical forms was not significant $(P=$ 0.0749 ), a larger number of cases occurred in the carnitinetreated group. This could be explained as a result of carnitine interference in the natural evolution of diphtheric myocarditis, halting the pathogenic process so that further clinical, electrocardiographic or radiological signs were not evident.

As expected, CK-MB values in both groups were not statistically different, which may indicate that myocarditis is intrinsic to diphtheria and will occur independently of the treatment. One may observe a higher incidence of myocarditis in this work compared to previous reports on the subject $(4,12)$. This may be a result of higher accuracy in myocarditis evaluation as evidenced by the determinations of CK-MB activities. Its higher cardiac specificity made possible confirmation of myocardial damage when other methods showed nonspecific and inconclusive findings, such as slight reductions of cardiac sound intensity (four cases), tachycardia (three cases), and discrete $\mathrm{T}$ wave alterations ( 14 cases).

The administration of carnitine resulted in decreased incidence of severe forms of myocarditis. Cardiac failure reduction was 
CLINICAL, RADIOLOGICAL, ELECTROCARDIOGRAPHIC AND

ENZYMATIC DIAGNOSIS

CPK-MB DIAGNOSIS

NO DIAGNOSIS
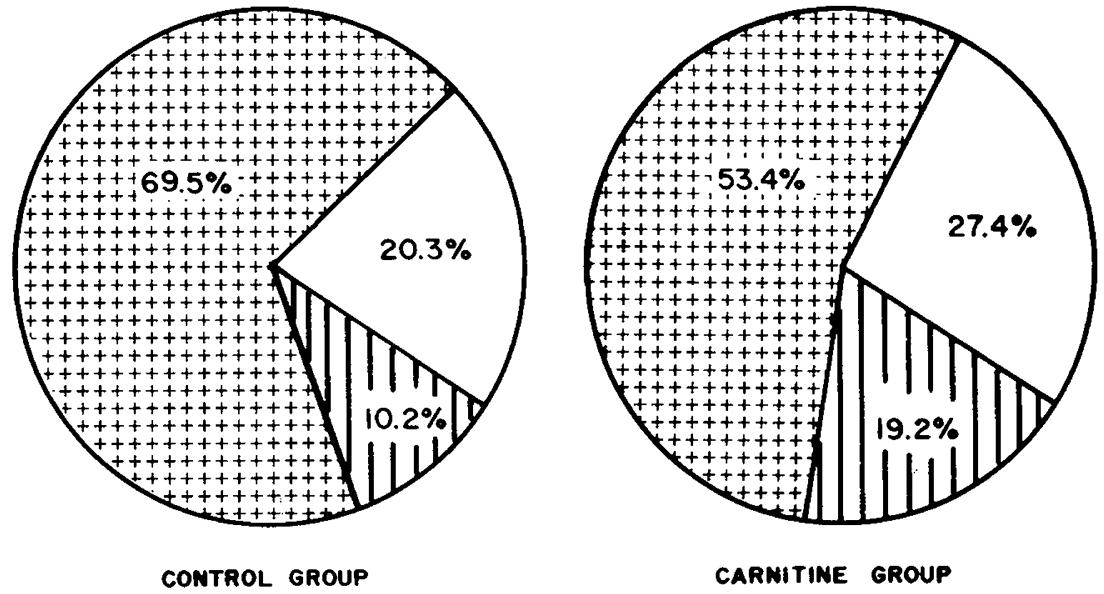

Fig. 2. Overall incidence of myocarditis. No significant difference was observed between the control group and the carnitine-treated group when myocarditis was diagnosed by all methods: clinical, radiological, electrocardiological, and enzymatic assays $(P=0.1736)$. There was no significant difference either between the control group (six children) and the carnitine-treated group (14 children) when only CK-MB assessment ensured cardiac injury diagnosis $(P=0.074)$.

Table 4. Specific causes of death in diphtheric patients of control and carnitine-treated groups

\begin{tabular}{lcc}
\hline & \multicolumn{2}{c}{ Number of cases } \\
\cline { 2 - 3 } Causes of death & Control & $\begin{array}{c}\text { Carnitine- } \\
\text { treated }\end{array}$ \\
\hline Myocarditis* & 8 & 2 \\
Respiratory failure & 1 & 1 \\
Pneumonia & & 1 \\
Digestive hemorrhage & & 1 \\
Sepsis & & 1 \\
Overall mortality $\dagger$ & 9 & 6 \\
\hline
\end{tabular}

\footnotetext{
* $P=0.013$.

$\dagger P=$ not significant.
}

reflected in therapeutics, where fewer patients needed diuretics and/or digitalis. The decrease in the need of temporary pacemakers with patients with severe conduction disorders in the carnitine-treated group was an important achievement since advanced disturbances in atrioventricular conduction are the most frequent causes of death in diphtheria $(9,14)$. But the clearest evidence of the positive action of carnitine therapy was the significantly lower incidence of myocarditis as the specific cause of the patients' death. As a result, only $33.3 \%$ of the treated patients died of myocarditis whereas $89 \%$ of patients in the control group failed to survive by this specific cause.

The use of DL-carnitine instead of L-carnitine as would be desired was adopted because it was the only pharmaceutic form available to us. It is important to mention that the concentration of DL-carnitine employed in the present therapy was 10-fold higher than that used for orexigen stimulation. Higher carnitine amounts were assumed to counterbalance a possible impairment in carnitine transport caused by the presence of the $D$ isomer. Nevertheless, the administration of DL-carnitine gave sufficient therapeutic support to show the above cited benefits, especially lower lethality indexes for the carnitine-treated patients. This study suggests that carnitine can play an important role in the treatment of those patients whose pathogenic mechanism involves carnitine depletion, as is likely in the case of diphtheria. On the other hand, further investigations should be performed in order not only to confirm this possible protective effect but to optimize this treatment approach.

Acknowledgments. The authors wish to express their gratitude to Prof. Nuno Alvares Pereira for the preparation of the carnitine medicine used in this work and to Profs. Roberto Cintra and Sonia Helt for the statistical support.

\section{REFERENCES}

1. Barksdale L 1981 Diphtheria bacilli and other corynebacteria. In: Braude A I (ed) Medical Microbiology and Infectious Diseases. Saunders, Philadelphia

2. Blalock HM 1972 Social Statistics, International Student Edition, McGrawHill, Kogakusha, Tokyo, pp 177-198

3. Bohmer T, Molstad P 1980 Carnitine transport across the plasma membrane. In: Frenkel RA (ed) Carnitine Biosynthesis, Metabolism and Functions. Academic Press, New York, pp 73-90

4. Boyer NH, Weinstein L 1948 Diphtheric myocarditis. N Engl J Med 239:913

5. Burch GE, Sun SC, Sohal RS, Chu KC, Colcolough NL 1968 Diphtheritic myocarditis, a histochemical and electron microscopic study. Am J Cardiol 21:261

6. Challoner DR, Mandelbaum I, Elliot W 197 I Protective effect of L-carnitine in experimental intoxication with diphtheria toxin. $\mathrm{J}$ Lab Clin Med 77:616

7. Challoner DR, Prols HG 1972 Free fatty acid oxidation and carnitine levels in diphtheric guinea pig myocardium. J Clin Invest 51:2071

8. Chapoy PR, Angelini C, Brown WJ, Stiff JE, Shug AL, Lederbaum SD 1980 Systemic carnitine deficiency. A treatable lipid storage disease presenting as Reyes' syndrome. N Engl J Med 303:1389

9. Christie AB 1977 Infectious Diseases. Epidemiology and Clinical Practice. Churchill Livingstone, New York

0. Collier RJ 1975 Diphtheria toxin: mude of action and structure. Bacteriol Rev 39:54

11. Klebs E 1883 Veber Diphtherie: Verhandlungen des Congresses für Innere Medizin. Vol 1, p 139

12. Ledbetter MK, Cannon AB, Costa AF 1964 The electrocardiogram in diphtheric myocarditis. Am Heart J 68:599

13. Maranhão EA 1981 Emprego do marcapasso provisório na miocardite diftérica. MS thesis, Universidade Federal do Rio de Janeiro 
14. McCloskey R 1979 Corynebacterium species (including diphtheria). In: Mandell GL (ed) Principles and Practice of Infectious Diseases. Wiley, New York

15. Opie LH 1968 Metabolism of the heart in health and disease. Am Heart J 76:685

16. Pappenheimer AM 1977 Diphtheria toxin. Annu Rev Biochem 46:69

17. Rebouche CJ, Engel AG 1980 Tissue distribution of carnitine. Biosynthetic enzymes in man. Biochim Biophys Acta 630:22

18. Tripp M, Katchel M, Peters H, Gilbert E, Arya S, Hodach R, Shug AL 1981
Systemic carnitine deficiency presented as familial endocardial fibroelastosis. N Engl J Med 305:385

19. Wittels B, Bressler R 1965 The effect of diphtheria toxin on carnitine metabolism in the heart. Biochim Biophys Acta 104:39

20. Wurzburg U, Henrich N, Orth HD, Lang H, Prellwitz W, Neumeier D, Knedel M, Rick W 1977 Quantitative determination of creatine kinase isoenzyme catalytic concentrations in serum using immunological methods. J Clin Chem Clin Biochem 15:131

\title{
Regulation of Upper Airway Maintaining Muscles during Progressive Asphyxia
}

\author{
O. P. MATHEW, B. T. THACH, Y. K. ABU-OSBA, R. T. BROUILLETTE, AND J. L. ROBERTS \\ Department of Pediatrics, University of Texas Medical Branch, Galveston, Texas and Washington University \\ School of Medicine, St. Louis Children's Hospital, St. Louis, Missouri 63110
}

\begin{abstract}
Summary
The electromyographic activity of an upper airway muscle (genioglossus, GG) and the diaphragm were studied in 10 adult and three young anesthetized rabbits during progressive asphyxia induced by airway occlusion. Results were similar for both age groups. Peak inspiratory activity of GG muscle increased more than that of the diaphragm during both the hyperpnea and gasping $(P<0.05)$. The increase in GG activity during gasping was not significantly different from that during hyperpnea even though an important stimulus, arousal, was absent during gasping. During end stage asphyxia, as the strength of gasps grew weaker, the rate of loss of GG muscle activity was greater than that of the diaphragm. However, GG activity remained greater than that of the diaphragm at the time of the last spontaneous gasp. As asphyxia progressed, inspiratory duration and the inspiratory contour of integrated electromyogram activity of both muscles changed. These data indicate differences in the control mechanism of the genioglossus and diaphragm during acute severe asphyxia. Increased upper airway muscle activity seen during gasping should help preserve upper airway patency and facilitate autoresuscitation by gasping. These observations of coordinated changes in timing and activity of two functionally different respiratory muscles support the concept that gasping is a highly organized function of the respiratory centers.
\end{abstract}

\section{Abbreviations}

DIA, diaphragm

EMG, electromyogram

GG, genioglossus

Recent observations suggest that pulmonary ventilation requires the coordination of thoracic and upper airway respiratory muscles. Contraction of upper airway dilating muscles prevents

Received November 29, 1983.

Supported in part by grants from National Institutes of Health, HD 10993 and from the American Lung Association.

Correspondence should be addressed to Dr. O. P. Mathew, Perinatal Pediatrics, University of Texas Medical Branch, Galveston, TX 77550. airway closure by counteracting the airway constricting effects of the negative pressure $(1,8,10,16,22)$. When the activity of the airway dilating muscles is depressed relative to that of the thoracic muscles, as occurs during general anesthesia (17), the normal balance is upset and airway collapse can occur. Upper airway obstruction is believed to prolong an apneic spell when asphyxia depresses upper airway muscle activity, presumably by the loss or delay of the arousal response $(18,25)$. Lacking direct observations to support or refute this theory, we have studied the inspiratory time course and peak electromyographic activity of an airway dilating muscle, the genioglossus, and an inspiratory pressure generating muscle, the diaphragm, during progressive asphyxia in an animal model. In these studies we have paid particular attention to the terminal events during asphyxia when failure in the strength of respiratory efforts begins to occur.

\section{MATERIALS AND METHODS}

Ten adult New Zealand White rabbits (weight, $1.5-4 \mathrm{~kg}$ ), anesthetized with pentobarbital (25-40 mg intraperitoneally) and three 4-week-old rabbits (weight, $0.5-0.6 \mathrm{~kg}$ ) anesthetized with urethane $(0.65-1.0 \mathrm{~g} / \mathrm{kg})$ were studied. The animals were studied supine with the head fixed at a $90^{\circ}$ angle to the spine. The rectal temperature was maintained between 38 and $39^{\circ} \mathrm{C}$ with an overhead lamp. Fine bipolar wire electrodes (38-gauge, Isomid Beldon) were used to record diaphragm (DIA) and genioglossus (GG) electromyograms (EMG). The diaphragmatic electrodes were inserted through a subcostal incision which was subsequently closed. An anterior midcervical incision was made through the skin and superficial fascia to expose the myelohyoid muscle and the GG electrodes were inserted through the myelohyoid as reported previously (1). EMG signals were amplified (Grass P15 AC preamplifier) filtered, rectified, and integrated. Animals breathed spontaneously through a tracheal cannula. After recording control activity of DIA and GG, the tracheal airway was occluded. Occurrence of arousal, onset of primary apnea, and the onset of gasping were noted on the record. Arousal was said to occur if there were spontaneous body movements, changes in tone of muscles of the head and neck, or eye movements. Direct and integrated EMGs as well as tracheal pressures were recorded on a polygraph. In three of 10 adult rabbits, 